\title{
Long period channel waves from records of Friuli (Italy) earthquakes in 1976
}

\author{
B. Alessandrini* ${ }^{*}$ P.F. Biagi ${ }^{* *}-$ M. Caputo***
}

Received on December 6th, 1981

\begin{abstract}
S
We present a study of a group of long period waves excited by the earthquakes of Friuli (Italy) in 1976 and recorded between longitudinal and transverse body waves by Long-period seismographs at epicentral distances up to about $3000 \mathrm{Km}$. The spectral analysis has permitted us to determine periods of the main phases which make up the wave group. In regard to the longer period phase, which appears first in the recordings, the velocity obtained by the dromochrones equals $8.4 \mathrm{Km} / \mathrm{s}$. The group velocity is instead $7.4 \mathrm{Km} / \mathrm{s}$. Such phases have been considered as being longitudinal channel waves in the astenosphere. Such hypothesis explains the inconsistencies which had appeared in previous studies on channel waves in the astenosphere.
\end{abstract}

* Istituto Nazionale di Geofisica - Osservatorio di Monte Porzio Catone (Roma).

** Istituto di Geologia e Paleontologia - Università di Roma.

*** Istituto di Fisica - Università di Roma. 


\section{RIASSUNTO}

Presentiamo lo studio di un gruppo di onde a lungo periodo originate aal terremoto del Friuli (Italia) nel 1976 e registrate tra le onde longitudinali e le trasversali da sismografi L.P. a distanza epicentrale di circa $3000 \mathrm{~km}$.

L'analisi spettrale permette di determinare i periodi della fase principale del gruppo d'onda.

Per quanto riguarda la fase a più lungo periodo, che appare prima nelle registrazioni, otteniamo dalle dromocrone una velocità pari a $8.4 \mathrm{~km} / \mathrm{sec}$.

La velocità di gruppo è invece $7.4 \mathrm{~km} / \mathrm{sec}$.

Tali fasi sono considerate come onde longitudinali canalizzate nellastenosfera. Questa ipotesi elimina le difficoltà apparse nei precedenti studi sulle onde canalizzate.

\section{INTRODUCTION}

The longitudinal channel waves in the astenosphere $\left(P_{a}\right)$ were discovered for the first time by Caloi (1953). Further results on the subject have been presented for example, by Caloi (1954, 1965), Gutenberg $(1953,1959,1959)$, Khorosheva-Magnitsky (1961), Guidroz-Baker (1963).

These waves, with periods in the range between $5 \mathrm{~s}$ and $20 \mathrm{~s}$, have been observed between longitudinal and transverse body waves on seismographs recorded at epicentral distances between $3000-15000 \mathrm{Km}$, for earthquakes at focal depth of not over $250 \mathrm{Km}$.

The velocity by the dromochrone is $8.0-8.3 \mathrm{Km} / \mathrm{s}$.

An aspect of the channel waves which still causes concern is the minimum epicentral distance $(3000 \mathrm{~km})$ where such phase was observed. If the ideal condition for channeling is represented by the fact that the energy is supposed to be let in the layer parallel to its limiting surfaces (or at least with such inclination as to force it to rythmically return within the layer), then, for normal earthquakes, channel waves should be observed even at 
those distances where body waves $P_{n}$ are clearly detected, thus much closer than $3,000 \mathrm{Km}$.

Another aspect of the results raises perplexities. In fact the velocity of the $P_{a}$ waves should be equal the minimum velocity within the channel. Presently such value, relative to earth models (Haddon-Bullen, 1969; Mizutani-Abe, 1972; Press, 1970), based on new information obtained by the observations of free oscillation is indicated at $7.7 \mathrm{Km} / \mathrm{s}$. Whereas, the velocity values $(8.0-8.3$ $\mathrm{Km} / \mathrm{s}$ ) obtained in the studies above mentioned on the channel waves are systematically higher.

Caloi (1965) was aware of this discrepancy and corrected the values obtained from the dromochrones and considered them as values of apparent velocity. Such correction, which is $-0.2 \mathrm{Km} / \mathrm{s}$ for a minimum at a depth of $150 \mathrm{Km}$, alothough it reduces the discrepancies, does not solve such discrepancy completely. Furthermore, the initial hypothesis which is the basis of the correction is not fully justified unless one admits the existence of a sloping channel.

Herein we intend to assume $P_{a}$ is a group of long period waves, which so far has not been examined, and to study those excited by the 1976 Friuli earthquake which were recorded by L.P. seismographs at stations with epicentral distance up to about $3,000 \mathrm{Km}$, shortly after the $P_{n}$ and before $S_{n}$.

\section{Principal CHARACTERISTICS OF THE WAVES}

The stations whose recordings have been used as well as the epicentral distances are given in table 1.

Figure 1 shows some of the seismograms which have been recorded following the earthquake of 6/5/1976 at Athens and Ponta Delgada stations, at a distance of $1,250 \mathrm{Km}$ and 3,300 Km respectively. In the first case, shown in figure $1 \mathrm{a}$, these waves are clearly marked whereas in the second case, shown in figure $1 \mathrm{~b}$, their amplitude appears considerably reduced.

The initial part of the recordings (preceeding the $S$ phase) obtained at some stations for the same earthquakes has been digitized. 
TABLE 1

\begin{tabular}{|c|c|c|}
\hline EARTHQUAKE & SEISMIC STATION & $\Delta(\mathrm{Km})$ \\
\hline $\begin{array}{l}\text { Sept. } 15 \mathrm{th}, 1976 \\
H=03.15 .19 \\
\varphi=46^{\circ} 16^{\prime} 36^{\prime \prime} \\
\lambda=13^{\circ} 08^{\prime} 27^{\prime \prime} \\
h=6.1 \\
\text { Sept. } 15 \mathrm{th}, 1976 \\
H=09.21 .18 \\
\varphi=46^{\circ} 20^{\prime} 42^{\prime \prime} \\
\lambda=13^{\circ} 10^{\prime} 26^{\prime \prime} \\
M=6.0 \\
\text { May } 6 \mathrm{th}, 1976 \\
H=20.00 .15,5 \\
\varphi=46^{\circ} 16^{\prime} 30^{\prime \prime} \\
\lambda=13^{\circ} 06^{\prime} 00^{\prime \prime} \\
M=6.4\end{array}$ & $\begin{array}{l}\text { Moxa } \\
\text { Krakow } \\
\text { De Bilt } \\
\text { Uppsala } \\
\text { Eilat } \\
\\
\text { Krakow } \\
\text { De Bilt } \\
\text { Uppsala } \\
\text { Kajaani } \\
\text { Eilat } \\
\\
\text { Gottingen } \\
\text { Uzhgorod } \\
\text { De Bilt } \\
\text { Lvov } \\
\text { Athens } \\
\text { Kongsberg } \\
\text { Eskdalemuir } \\
\text { Nurmijarvi } \\
\text { Valentia } \\
\text { Porto } \\
\text { Pulkovo } \\
\text { Sochi } \\
\text { Kajaani } \\
\text { Eilat } \\
\text { Kevo } \\
\text { Ponta Delgada }\end{array}$ & $\begin{array}{r} \\
630 \\
740 \\
870 \\
910 \\
1270 \\
1510 \\
1520 \\
1760 \\
1810 \\
1830 \\
1890 \\
2110 \\
2190 \\
2660 \\
2730 \\
3310\end{array}$ \\
\hline
\end{tabular}




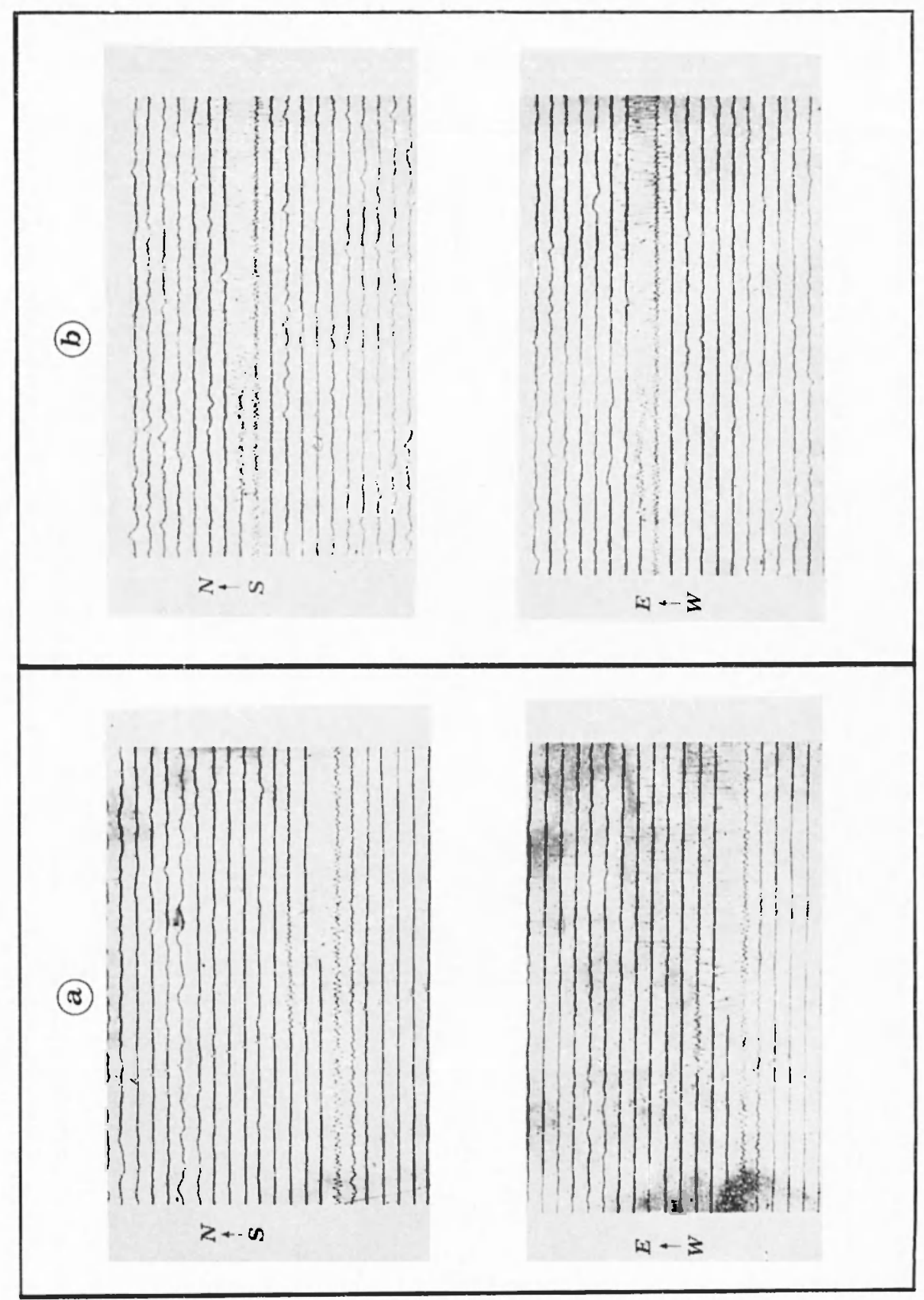

Figure 1 - Friuli earthquake of $6 / 5 / 1976$. Initial part of the recordings of the horizontal components at the seismic stations of:

a) Athens $(\Delta=1250 \mathrm{Km})$;

b) Ponta Delgada $(\Delta=3300 \mathrm{Km})$. 


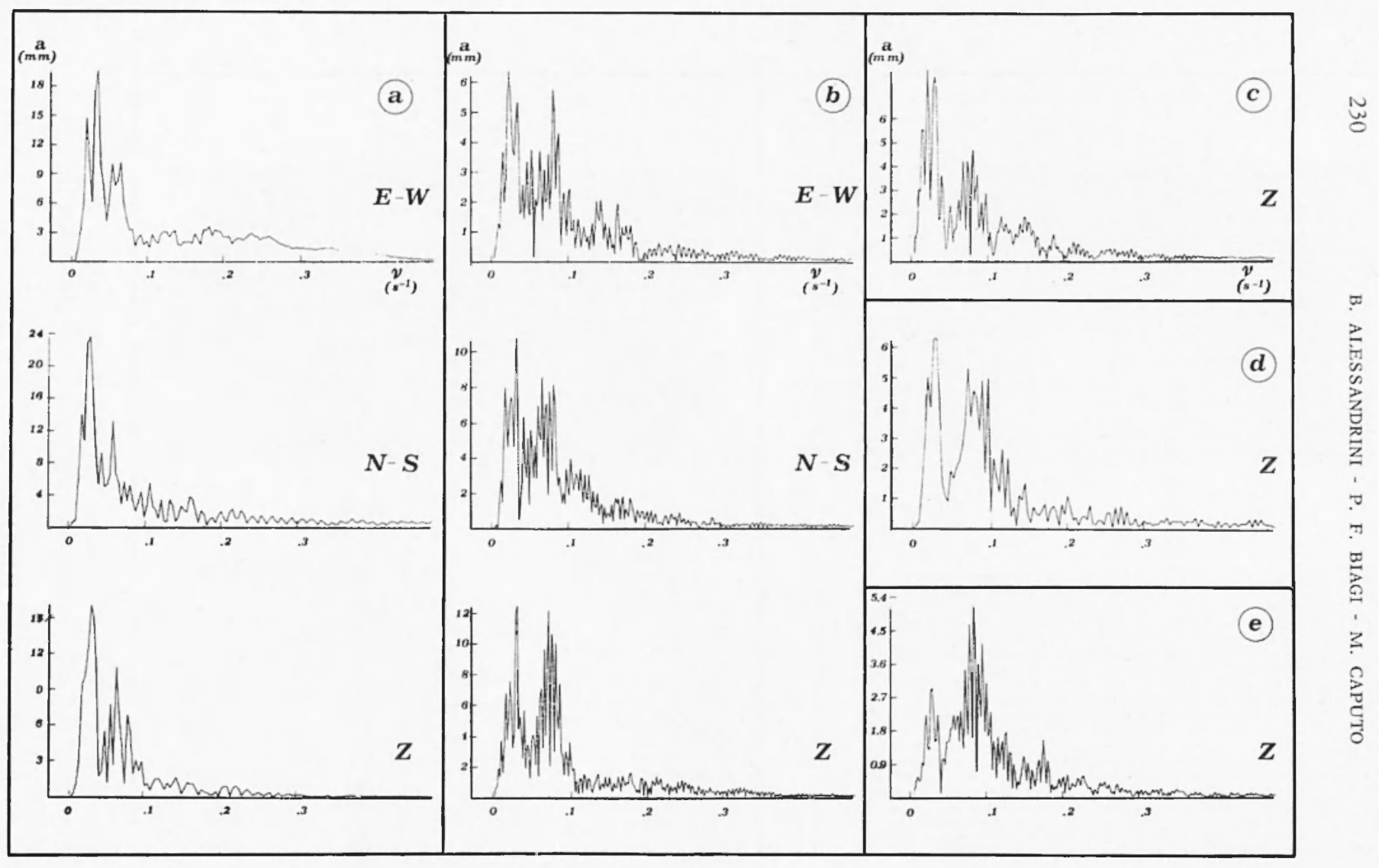

Figure 2 - Fourier transforms of the part preceeding phases $S$ of the recording obtained at some seismic stations for the same earthquakes. The ordinate shows the recorded amplitude.

a) Athens (ATH), earthquake of $6 / 5 / 1976$;

b) Nurmijarvi (NUR), earthquake of 6/5/1976;

d) and e) Uppsala (UPP), earthquakes of $15 / 9 / 1976$

c) Eskdalemuir (ESK), earthquake of $6 / 5 / 1976$; $(H=03.15 .19$ and $H=09.21 .18)$. 


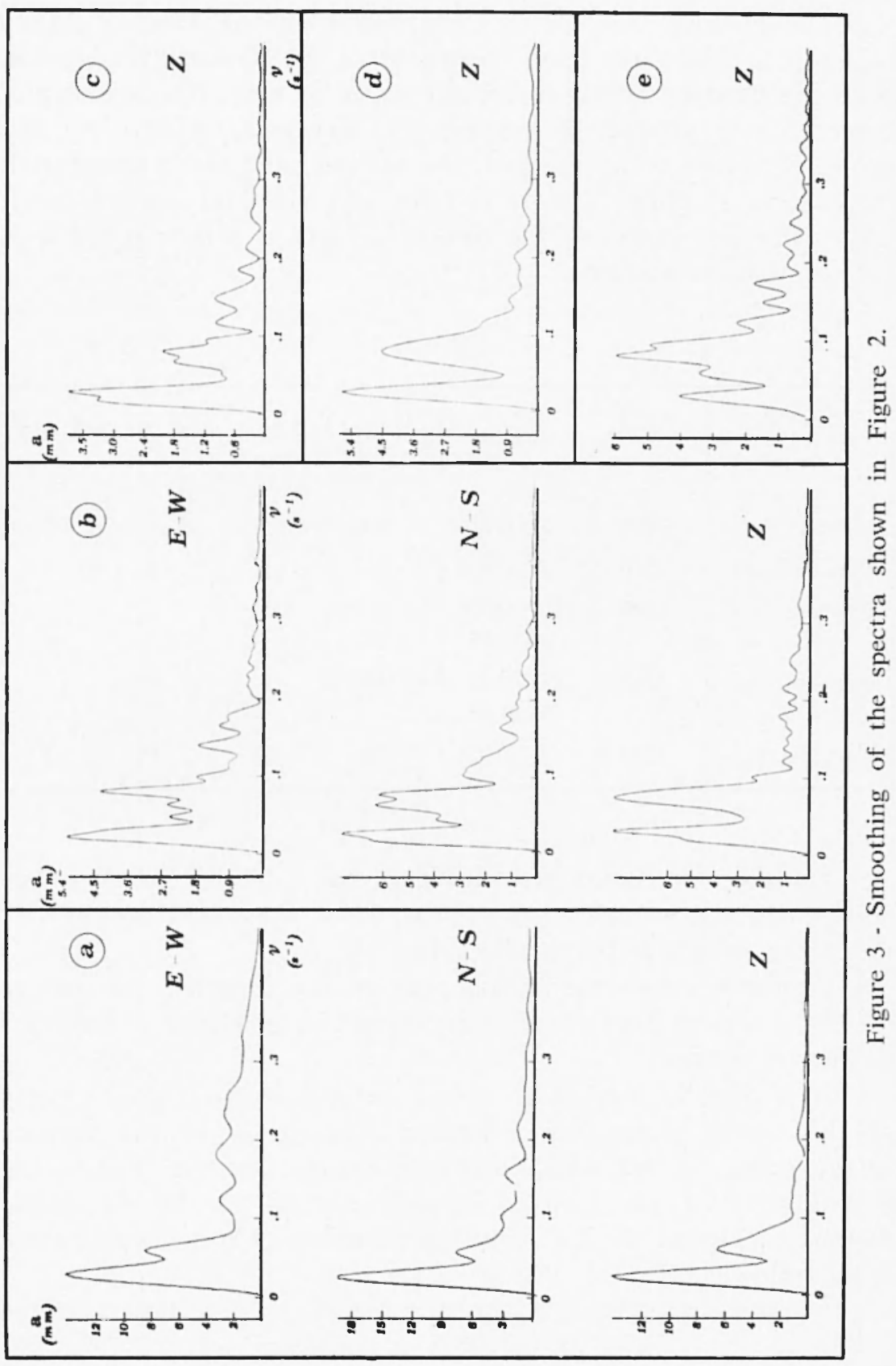


The Fourier transforms carried out on the data is shown in figure 2. The smoothing (figure 3 ) of the spectrum, obtained with the Ormsby (1961) filter, allows us to mark the separation between two groups of frequencies, the first, relative to the group of waves being studied, the second relative to the initial, lingitudinal $P_{n}$ phase. The mean value of the period $T$ corresponding to the first group of the smoothed data is shown in table 2 , for the various stations.

TABLE 2

\begin{tabular}{|c|c|c|c|c|c|c|}
\hline $\begin{array}{l}\text { Seismic } \\
\text { Station }\end{array}$ & $\Delta(\mathrm{Km})$ & $\begin{array}{l}\text { Earth- } \\
\text { quake }\end{array}$ & $T(s)$ & $T_{1}(s)$ & $T_{2}(s)$ & $T_{3}(s)$ \\
\hline Athens & 1270 & $6 / 5 / 1976$ & 40 & 51 & 37 & / \\
\hline Eskdalemuir & 1520 & $6 / 5 / 1976$ & 35 & 51 & 37 & 1 \\
\hline Uppsala & 1540 & $\begin{array}{c}15 / 9 / 1976 \\
03.15 .19\end{array}$ & 35 & 51 & 37 & I \\
\hline Uppsala & 1530 & $\begin{array}{c}15 / 9 / 1976 \\
09.21 .18\end{array}$ & 35 & 51 & 37 & 28 \\
\hline Nurmijarvi & 1760 & $6 / 5 / 1976$ & 29 & 57 & 43 & 30 \\
\hline
\end{tabular}

Table 2 also shows periods $T_{1}, T_{2}$ and $T_{3}$ of the single waves composing the groups; they appear to be the main elements of the group of waves being studied.

Figure 4 shows the initial part of the digitized recordings which have been filtered in the frequency range which determines the waves group.

It is also important to obtain information on the velocity of the waves group being studied. The study of the various seismograms has allowed us to note clearly that the time of the first arrival of such waves is proportional to the epicentral distances (Figure 5). The resulting equation of the dromochrone is as follows:

$$
t=0.2196 \Delta+0.6335
$$




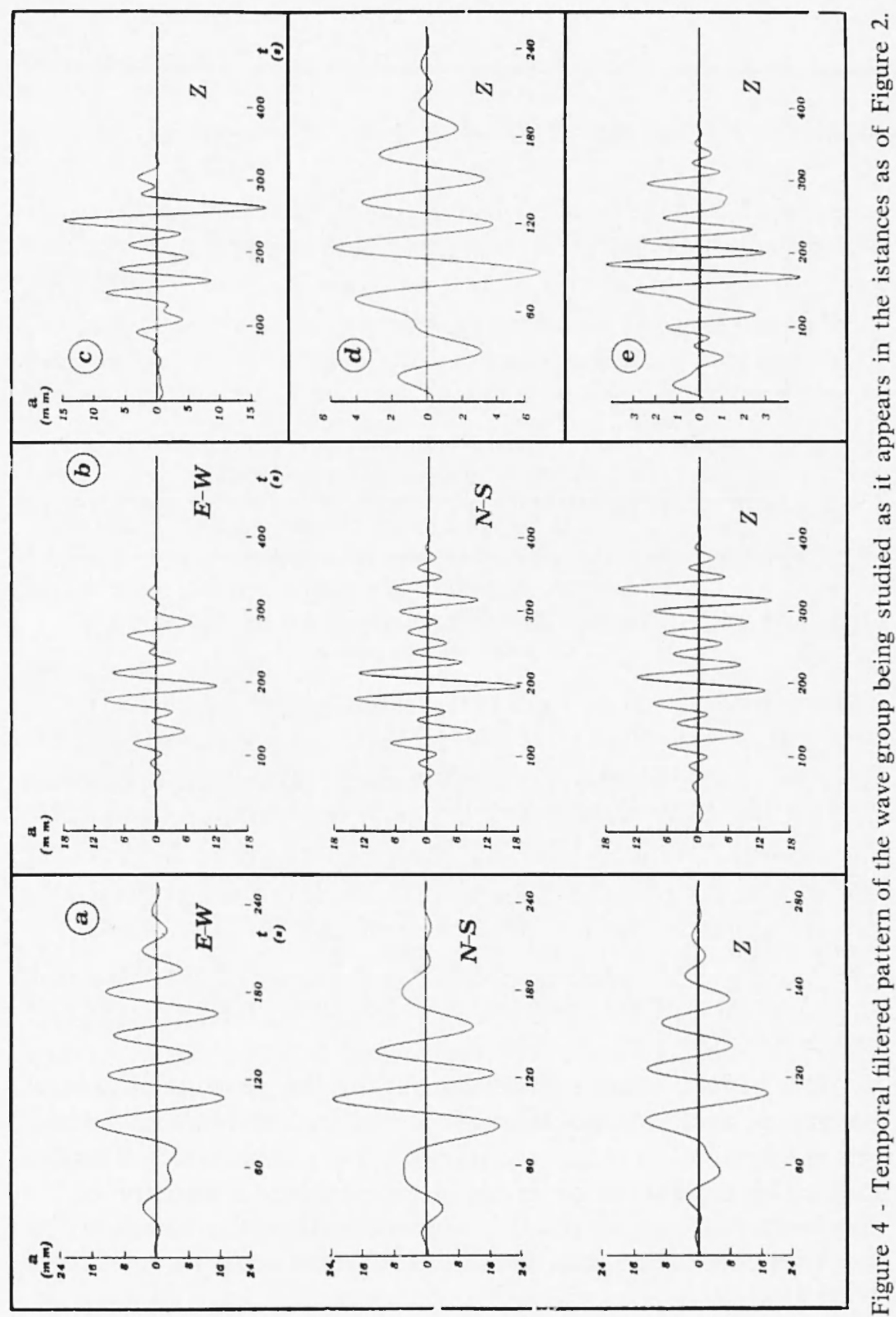




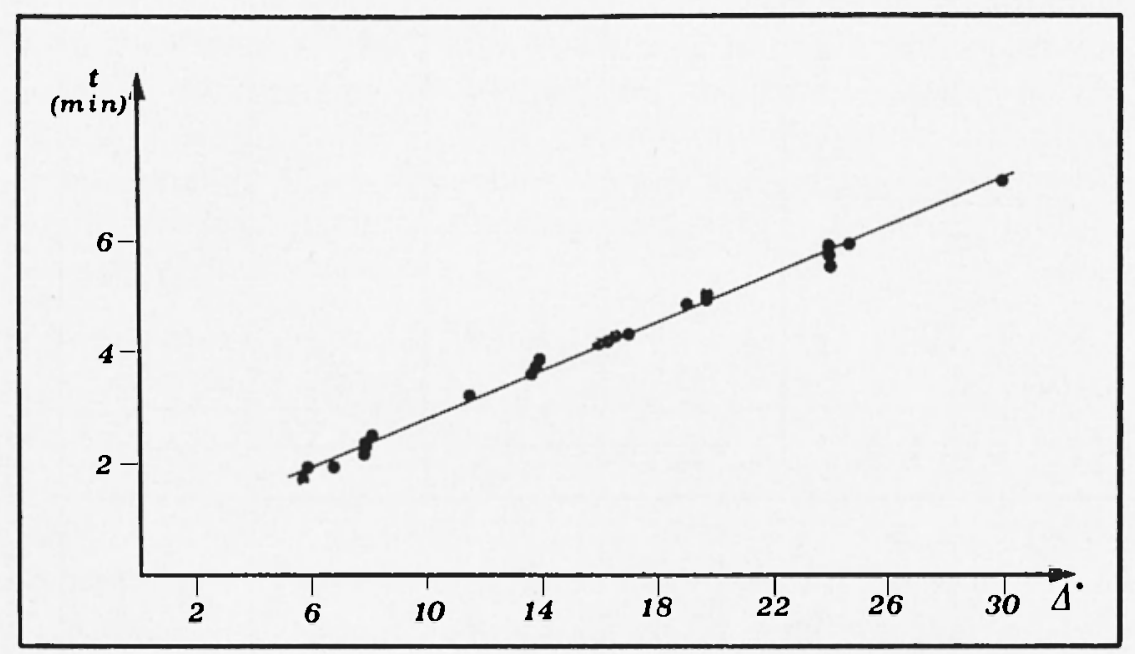

Figure 5 - Observed time-distance curve for the longer period phase of the group.

where $\Delta$ represents the epicentral distance (expressed in degrees) and $t$ is the time (expressed in minutes). The differences between the experimental values and the corresponding ones given by [1] are at most $0.3 \mathrm{~min}$. The main cause of the scattering of the results can be found in the fact that even though the waves group is clearly singled out in seismograms, the first phase in the group is not often distinct. Relation [1] implies a phase velocity of $(8.4+0.1) \mathrm{Km} / \mathrm{s}$.

We have also considered the maximum wave amplitude of the group; we have utilized only the digitized and filtered seismo. grams (figure 4) in order to obtain homogeneous and significative data. The arrival times of the maxima give a velocity of 7.4 $\mathrm{Km} / \mathrm{s}$. It must be pointed out however, that the data are few for a reliable evaluation, therefore this value must be considered tentative. 


\section{CONCLUSIONS}

The characteristics of the waves group under study have resulted as follows:

a) the group of waves is well detectable in all three components of the recording at epicentral distances between 400 $3000 \mathrm{Km}$;

b) there are three principal phases of the group and their periods are in the range $57-28 \mathrm{sec}$, with negligible variations with the azimuth and the distance of the station;

c) the group velocity appears to be $7.4 \mathrm{Km} / \mathrm{s}$, while the phase with greater period, which appears first, has a velocity of $8.4 \mathrm{Km} / \mathrm{s}$;

d) the amplitude of the phase with shorter period seems to increase as the epicentral distance increases.

Groups of waves with these characteristics have not been interpreted yet.

The velocity values indicate that these waves are longitudinal. We feel that they are being longitudinal waves channeled within the astenosphere. Therefore the phases which have been examined seem to be the expression to little epicentral distances of such channeled waves, which have been studied by other authors.

In conclusion, the low velocity channel which is responsible for the channeling seems to include waves with period from $60 \mathrm{sec}$ to a few seconds; the energy seems to gradually move to higher frequencies as the epicentral distance increases. The latter phases, which are imperceptible (at the closer stations) compared to those at a longer period as the examined recordings shows, have been marked in previous studies on the subject whereby the analysis has been made in regardings at greater epicentral distances.

It is worthwhile pointing out that we have hereby obtained in regard to the $P_{a}$ considered as wave group, a velocity value which is not greater than the minimum value in the astenosphere, contrary to what had appeared in the preceeding studies. 


\section{REFERENCES}

Calor, P., 1953 - Onde longitudinali e trasversali guidate dall'astenosfera. Rend. "Accademia Naz. dei Lincei", serie VIII, vol. XV, fasc. 6.

CALoI, P., 1954 - L'astenosfera come canale guida dell'energia sismica. "Annali di Geofisica ", VII, 4.

CaloI, P., 1965 - On the canalization of seismic energy. "Annali di Geofisica ", XVI, 1.

Gutenberg, B., 1953 - Low-velocity layers in the Earth's Mantle. "Bull. Seismol. Soc. Amer.", 43, pp. 223-232.

GUTENBERG, B., 1959 - The astenosphere low velocity layer. "Annali di Geofisica ", XII, 4.

Gutenberg, B., 1959 a - Wave velocities below the Mohorovicic Discontinuity. "Geophys. Journ. of the R. Astron. Soc.", 2, 4.

Guidroz, R.R., BAKER, R.G., 1963 - Channel waves. Worldwide Collection and Evaluation of Earthquake Data. Report n. IV, Texas Instruments Inc., Dallas.

Haddon, R.A.W., Bullen, K.E., 1969 - An Earth model incorporating free Earth oscillation data. "Phys. Earth Planet. Interiors".

Khorosheva, V.V., Magnitsky, V.A., 1961 - The waveguide in the Mantle of the Earth and its probable physical nature. "Annali di Geofisica $"$ XIV.

Mizutani, H., ABE, K., 1972 - An Earth model consistent with free oscillation and surface data. "Phys. Earth Planet. Interiors".

ORMSBY, J.F.A., 1961 - Design of numerical filters with application to missile data processing. "Association for Computing Machinery Journal", 8, pp. $440-466$. 